\title{
Arsenic mitigation by chitosan-based porous magnesia- impregnated alumina: performance evaluation in continuous packed bed column
}

\author{
S. Saha ${ }^{1} \cdot$ P. Sarkar ${ }^{1}$
}

Received: 25 March 2014/Revised: 27 January 2015/Accepted: 16 March 2015/Published online: 28 April 2015

(C) Islamic Azad University (IAU) 2015

\begin{abstract}
Dissolved arsenic in contaminated groundwater is a major concern on a global scale due to its extreme toxicity. This paper reports a magnesium oxide-impregnated mesoporous alumina synthesized using biopolymer chitosan template. The adsorbent was first characterized by BET, SEM and EDAX analysis. The packed column performed effectively over wide range of $\mathrm{pH}$ and exhibited a maximum adsorption capacity of $17.2 \mathrm{mg} / \mathrm{g}$ for an input arsenic concentration of $20 \mathrm{mg} / \mathrm{L}$. The experimental data fitted well with pseudo-second-order kinetics. Thermodynamic study on the adsorption phenomena revealed that arsenic adsorption on the porous adsorbent was spontaneous, and the process was exothermic. The arsenic sorption capacity at breakthrough point was greatly dependent on bed depth. A bed depth service time approach was adopted to describe the continuous flow system. The column after exhaustion was regenerated by eluting the bound arsenate $[\mathrm{As}(\mathrm{V})]$ with $\sim 15$ bed volume sodium hydroxide solution. The adsorbent could retain its capacity up to five cycles of such regeneration. The influence of different operating conditions such as bed depth, flow rate and initial arsenic concentration was investigated statistically by the two-level full-factorial experimental designs to evaluate optimum operating conditions.
\end{abstract}

Electronic supplementary material The online version of this article (doi:10.1007/s13762-015-0806-1) contains supplementary material, which is available to authorized users.

\section{P. Sarkar \\ sarkarpriya@gmail.com}

1 Department of Polymer Science and Technology, University of Calcutta, 92 APC Road, Kolkata 700009, India
Graphical abstract

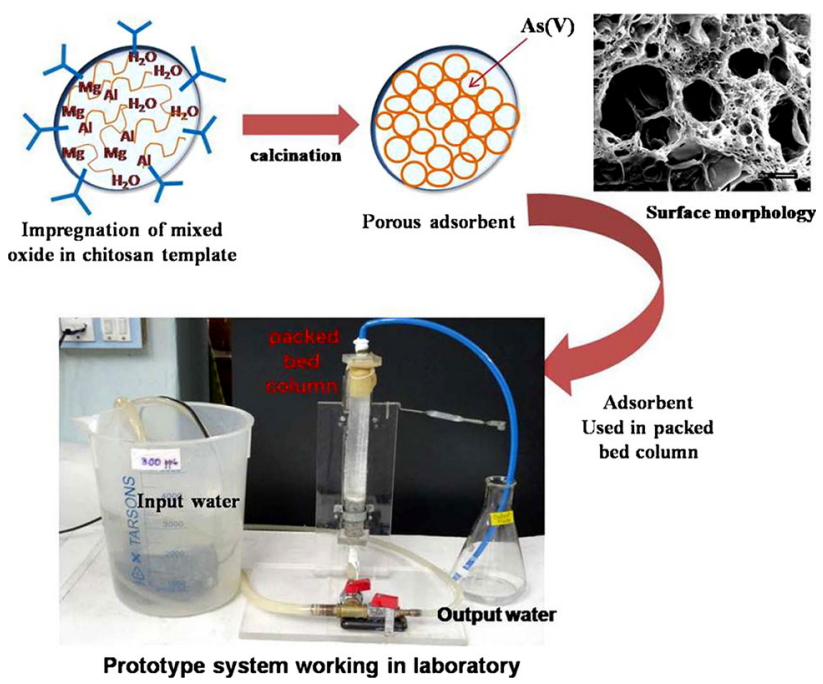

Keywords Adsorption - BDST model - Breakthrough · Drinking water $\cdot$ Factorial design

\section{Introduction}

The presence of dissolved arsenic in groundwater has gained international attention among scientists (WHO 1981). Exposure to arsenic-contaminated drinking water causes serious health problems. High arsenic content is found in ground water of Taiwan, India and Vietnam (Nickson et al. 1998). Arsenic is generally present as pentavalent $\left(\mathrm{H}_{3} \mathrm{AsO}_{4}, \mathrm{H}_{2} \mathrm{AsO}_{4}{ }^{-}, \mathrm{HAsO}_{4}{ }^{2-}\right)$ and trivalent $\left(\mathrm{H}_{3} \mathrm{AsO}_{3}, \mathrm{H}_{2} \mathrm{AsO}_{3}{ }^{-}, \mathrm{HAsO}_{3}{ }^{2-}\right)$ oxidation states (Ohki et al. 1996). 
Many researchers reported several heavy metal removal methods (Donga et al. 2011) that include chemical precipitation, ion exchange, membrane separation, adsorption, electrodialysis, etc. (Bissen and Frimmel 2003; Biati et al. 2014). Among these, adsorption is extensively adopted because of its simplicity and low-cost operation (Gupta et al. 2014; Wang et al. 2002). A number of adsorbents, e.g., activated alumina, activated carbon, calcite, red mud, ferric hydroxide, layered double hydroxides and several nanocomposites have been studied (Mohan and Pittman 2007; Ghaedi et al. 2012, 2013, 2014; Thirunavukkarasu et al. 2003; Boldaji et al. 2010; Matthew et al. 2003; Guo et al. 2007). But these adsorbents are not very effective due to their low sorption capacities and optimum performances at narrow $\mathrm{pH}$ range. Recently, the efficient removal capacities of biopolymers (Uzasc1 et al. 2014) and biodegradable particulate (Drewnowski and Makinia 2014) have also been reported for toxic metal ions. Porous materials are known for their high-adsorption capacities due to large surface area, narrow pore-size distributions and highly uniform channels (Kim et al. 2004). We have earlier reported nano-alumina-loaded chitosan-graft-polyacrylamide for arsenic removal with loading capacity $6.2 \mathrm{mg} / \mathrm{g}$ (Saha and Sarkar 2012). However, large-scale removal of arsenic requires higher adsorption capacity, and considering this fact, we have synthesized high-performance porous magnesia-impregnated alumina (MIPA) and studied remediation in continuous packed bed column. Here biopolymer chitosan was used as a template for synthesis of porous adsorbent (Zulfikar et al. 2014). The organic matter and carbon content of chitosan were eliminated during the calcinations, which helped to create porous structure. Chitosan thus played the key role in the formation of mesoporous structure of the adsorbent. This magnesia-impregnated alumina performed better than bare alumina in the removal of arsenic in water (Kuriakose et al. 2004). This new magnesium oxide-impregnated mesoporous adsorbent was prepared by a simple laboratory procedure. The adsorbent exhibited desirable adsorption characteristics such as high surface area, large pore volume, tunable porous structure with well-defined pore-size distribution, controllable wall composition, as well as modifiable surface properties. It was thermally as well as chemically stable and could be produced with identical properties. There was flexibility in post-functionalization with introduction of hydrophilic, hydrophobic, polar as well as positively or negatively charged functional moieties on the surface. Due its tortuous porosity, pore diffusion would be the limiting step (slow) in mass transfer process.

Most of the previous reports on arsenic adsorption considered batch processes. The removal of arsenic in continuous column systems is thought to be very useful due to long shelf life, less reagent handling and low-operating cost. The use of the packed bed for arsenic mitigation would be (1) continuous operation (2) easy control on throughput (3) uninterrupted operation using a standby column and (4) easy regeneration. Generally, arsenite content of water is first oxidized to arsenate before being fed to the adsorption column. Hence, speciation of arsenic was not necessary for packed bed column study. Breakthrough studies were carried out to evaluate the performance of porous beads by varying the operating conditions, such as the flow rate, bed depth and influent concentration. The Bohart and Adams equation (Bohart et al. 1920) was used for the estimation of the basic design parameters characterizing the performance of the dynamic process.

We conducted this research with essential objectives as evaluation of (1) the biosorption capacity of porous beads for the removal of As(V) in a packed bed column (2) the effect of different parameters in the adsorption process and (3) optimum process parameters by factorial design. This is the novel and significant part of our study, which was performed in the Department of Polymer Science and Technology (Biosensor Laboratory), University of Calcutta, India (2013-2014).

\section{Materials and methods}

\section{Materials}

Aluminum nitrate, magnesium chloride hexahydrate, chitosan (CTS) and sodium hydroxide were supplied by EMerck (Germany) and were used as received. The As(V) stock solution was prepared by dissolving sodium arsenate, $\mathrm{Na}_{2} \mathrm{HAsO}_{4} \cdot 7 \mathrm{H}_{2} \mathrm{O}$ purchased from Sigma (UK) in MilliQ water.

\section{Synthesis of magnesia-impregnated porous alumina using chitosan biopolymer (MIPA)}

Chitosan was first dissolved in $5 \%$ acetic acid at $70{ }^{\circ} \mathrm{C}$, and the solution was stirred for $3 \mathrm{~h} .2 \mathrm{M}$ aluminum nitrate was added to magnesium chloride $(2 \mathrm{M})$ solution in weakly acidic medium ( $\mathrm{pH} 4.5$ ) for $1 \mathrm{~h}$. This mixture was added to chitosan solution and continuously stirred for $4 \mathrm{~h}$ to form a homogenous mixture. This was dispensed into a gently stirred $1 \mathrm{M}$ solution of $\mathrm{NaOH}$ by a peristaltic pump at constant rate to form uniform spherical hydrogel beads of about $1.5 \mathrm{~mm}$ diameter. The spherical beads thus formed were stabilized for $1 \mathrm{~h}$ in $\mathrm{NaOH}$ solution and separated followed by a thorough wash with MillQ water and dried at $70{ }^{\circ} \mathrm{C}$. The dried beads were calcined at $500{ }^{\circ} \mathrm{C}$ for $6 \mathrm{~h}$ in the presence of air. After calcination, the remaining material was thoroughly washed with MilliQ water and dried at $100^{\circ} \mathrm{C}$. 


\section{Characterization}

Surface morphologies of the porous adsorbent were characterized by scanning electron microscopy (FEI company quanta 200) at $20 \mathrm{kV}$ volt and different magnifications. Elemental spectra were obtained using an energy dispersive X-ray analyzer (EDAX) during SEM observation. Surface area of mesoporous alumina was measured using Brunauer-Emmett-Teller (BET) method by $\mathrm{N}_{2}$ adsorption isotherms using Micrometrics ASAP 2010K surface area analyzer.

\section{Spectral characterization}

The FTIR spectra of samples were performed in a Thermo Scientific FTIR instrument (Model Nicolet iS 10) using ATR sampling technique. The spectra over the range $4000-400 \mathrm{~cm}^{-1}$ were obtained at a resolution of $4 \mathrm{~cm}^{-1}$.

\section{X-ray diffraction}

The wide-angle X-ray scattering (WAXS) was performed using XPERT-PRO wide-angle X-ray diffractometer (USA) in reflection mode. The instrument was operated at a $40-\mathrm{kV}$ voltage and a 30-mA current using Ni-filtered $\mathrm{Cu}-\mathrm{k} \alpha$ radiation $(\lambda=1.54 \AA)$. The samples were scanned from $2 \theta=20^{\circ}-90^{\circ}$ at the step scan mode to record the diffraction pattern.

\section{Determination of loading capacity of adsorbent}

Quantitative determination of arsenic was accomplished by a UV-Vis spectrophotometer at $880 \mathrm{~nm}$ following molybdenum blue method in the higher concentration range, i.e., $\mathrm{mg} / \mathrm{L}$ (Lenoble et al. 2003) and by a PST-KIT developed in our laboratory (Das et al. 2014) in the lower concentration range, i.e., $\mu \mathrm{g} / \mathrm{L}$. In each experiment, the arsenic-spiked water in the airtight Erlenmeyer flask $(25 \mathrm{~mL})$ was allowed to equilibrate with polymeric beads in orbital shaker at $150 \mathrm{rpm}$. The amount of arsenic adsorbed $(\mathrm{mg})$ per gram of polymer beads $q_{\mathrm{e}}$ was obtained using the equation

$q_{\mathrm{e}}=\left(C_{\mathrm{i}}-C_{\mathrm{e}}\right) V / M$

where $C_{\mathrm{i}}$ and $C_{\mathrm{e}}$ are initial and equilibrium concentrations in $\mathrm{mg} / \mathrm{L}, M$ is the dry mass of adsorbent-encapsulated polymer beads in grams, and $V$ is volume of solution in liters.

\section{Determination of isoelectric point of the adsorbent}

The isoelectric points of MIPA and As(V)-adsorbed MIPA were determined at different $\mathrm{pH}$ by measuring zeta potential of the particles using Malvern Zeta-sizer Nano ZS90, UK. In this experiment, $0.1 \mathrm{~g}$ adsorbent was added to $50 \mathrm{~mL}$ of $0.01 \mathrm{M} \mathrm{NaNO}_{3}$ solution and agitated with magnetic stirrer. The required $\mathrm{pH}$ of the solution was adjusted by $\mathrm{NaOH}$ or $\mathrm{HCl}$.

\section{Kinetic study}

In order to estimate equilibrium adsorption rate of arsenic by porous adsorbent, time-dependent sorption studies were conducted. Adsorption kinetics were monitored by adding $0.15 \mathrm{~g}$ of MIPA into a $100 \mathrm{~mL}$ solution of $25 \mathrm{mg} / \mathrm{L}$ of $\mathrm{As}(\mathrm{V})$ and stirred at $150 \mathrm{rpm}$. A portion of solution mixture $(5 \mathrm{~mL})$ was withdrawn from the bulk at predetermined time intervals, filtered, and analyzed for the concentration of $\mathrm{As}(\mathrm{V})$ using molybdenum blue method (Lenoble et al. 2003).

\section{Thermodynamic study}

Thermodynamic studies were carried out by fixing the adsorption temperature at 298,313 and $333 \mathrm{~K}$ with $0.15 \mathrm{~g}$ adsorbent in $50 \mathrm{~mL}$ of arsenic-spiked $(25 \mathrm{mg} / \mathrm{L})$ water.

\section{Fixed-bed column study}

Dynamic adsorption studies were conducted by a fixed-bed column made of transparent polymethyl methacrylate (PMMA) thermoplastic pipe (1.5 cm I.D.) with a total bed height of $24.5 \mathrm{~cm}$. A peristaltic pump was employed to feed the column with As(V)-spiked water (initial concentration $0.3 \mathrm{mg} / \mathrm{L}$ ) through the MIPA packed column in the up-flow mode at desired flow rates $(6,10$ and $20 \mathrm{~mL} / \mathrm{min})$. Samples were collected at different bed heights and analyzed for the residual concentration of arsenic. Analysis of breakthrough curve was accomplished by bed depth service time (BDST) model. Empty bed contact time (EBCT), a critical parameter that determines the residence time, was found to be 7.2, 4.32 and $2.163 \mathrm{~min}$ corresponding to flow rates of 6,10 and $20 \mathrm{~mL} / \mathrm{min}$.

\section{Regeneration of column}

As(V)-exhausted MIPA could be regenerated using $\mathrm{NaOH}$. Exhausted bed was charged with $0.1 \mathrm{M} \mathrm{NaOH}$ solution with up-flow rate of $10 \mathrm{~mL} / \mathrm{min}$ until the adsorbed $\operatorname{As}(V)$ was recovered. Subsequently, the bed was reconditioned with MillQ water until the $\mathrm{pH}$ of the effluent water reached 7.0. The bed was then recharged with $\mathrm{As}(\mathrm{V})$-spiked water for performance evaluation. Temperature of $25{ }^{\circ} \mathrm{C}$ and $\mathrm{pH} 7.5$ was maintained in these experiments. 


\section{Statistical optimization}

The factorial design was used to find the impact and the variation of factors that influenced the output or response. In this work, volumetric flow rate, initial $\mathrm{As}(\mathrm{V})$ concentration and bed height were considered as independent variables, while the temperature $\left(25^{\circ} \mathrm{C}\right)$ and $\mathrm{pH}$ were kept constant. The percentage removal of arsenic was considered as the output response. Two replicates of $2^{3}$ full-factorial design (FFD) having eight experiments (with each replicate) were studied.

\section{Results and discussions}

\section{Characterization of adsorbent}

\section{BET analysis}

Surface areas of both porous alumina (PA) and magnesiaimpregnated porous alumina (MIPA) were measured by BET analysis. $\mathrm{N}_{2}$ adsorption on porous adsorbent generated a type II isotherm (Fig. 1) as per the classification given by IUPAC (Brunauer et al. 1940; Rouquerol et al. 1994), and this was very different than the Langmuir model.

The flatter region (Fig. 1) in the middle represented the formation of a monolayer. Inflection point $(B)$ occurred near the completion of the first adsorbed monolayer and beginning of multilayer adsorption. A type II isotherm is obtained when $c>1$ in the BET equation. At very low pressures, the mesopores are filled with nitrogen gas. At the knee, monolayer formation is beginning and multilayer formation occurs at medium pressure. Capillary condensation may occur at high pressure. The BET surface area,

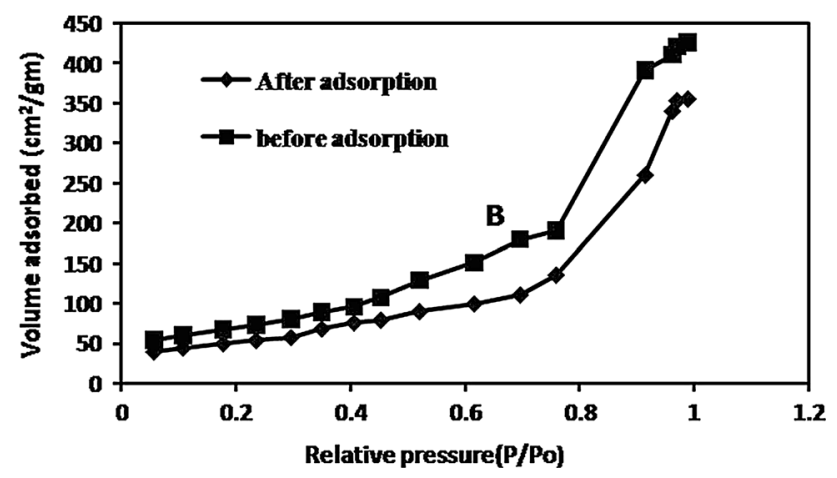

Fig. 1 BET isotherm of MIPA at $303 \mathrm{~K}$ average pore size and total pore volume of PA and MIPA are given in Table 1.

The increase in the surface area after impregnation was due to elimination of water molecule from mixed metal oxide as well as organic matter and carbon content of chitosan, creating more pores in the adsorbent. But in previous studies (Sushree et al. 2008), it was shown that the specific surface area of alumina decreased after impregnation. This difference in surface area of MIPA was unique presumably due to a different preparation technique applied. The BET surface area before adsorption was found to be $250.03 \mathrm{~m}^{2} / \mathrm{g}$, whereas some reduction in the BET surface area was observed after adsorption $\left(223.67 \mathrm{~m}^{2} / \mathrm{g}\right)$.

\section{SEM and EDAX analysis of adsorbent}

The surface morphologies of PA and MIPA were studied by SEM. No pores could be clearly seen before calcinations (Fig. 2a), whereas Fig. 2b suggests highly porous structure of alumina with smaller pore sizes. The virgin MIPA as depicted in Fig. 2c had a significantly rougher surface with lots of pores, and the surface was apparently occupied by the newborn manganese oxides formed during the impregnation process. The large surface area (i.e., high density of adsorption sites) and uniform porous structure with channels on these samples would definitely enhance their adsorption abilities in the water treatment. Figure $2 \mathrm{~d}$ shows the SEM of arsenate-adsorbed MIPA. Small particles of amorphous arsenate could be seen to adhere to the MIPA surface. To investigate the elemental analysis of adsorbent, EDAX was performed and shown in Fig. S1 (Supplementary material).

\section{$X$-ray diffraction analysis of adsorbent}

Powder X-ray diffraction (XRD) pattern of pristine chitosan and MIPA (before and after adsorption) is shown in Fig. S2 (Supplementary material). The XRD patterns of chitosan produced predominantly broad peaks at $2 \theta=10^{\circ}$, $20^{\circ}$. However, these peaks were not observed in MIPA due to the elimination of chitosan in the calcination step at $500{ }^{\circ} \mathrm{C}$, whereas some sharp peaks at $2 \theta=28.5,29,33.1$, 34 36.6, 40.6 indicated the presence of $\gamma$-alumina phase, whereas peaks at $2 \theta=45.16,53.16,55.9$ confirmed homogeneous impregnation of crystalline magnesium oxide in alumina. Further, the XRD pattern remained almost the same after arsenic adsorption, indicating retention of the
Table 1 Properties of porous adsorbent

\begin{tabular}{lcll}
\hline Sample & Loading capacity $(\mathrm{mg} / \mathrm{g})$ & BET-specific surface area $\left(\mathrm{m}^{2} / \mathrm{g}\right)$ & Average pore width $(\mathrm{nm})$ \\
\hline PA & 9.5 & 180.07 & 2.15 \\
MIPA & 17.2 & 250.034 & 6.7 \\
\hline
\end{tabular}



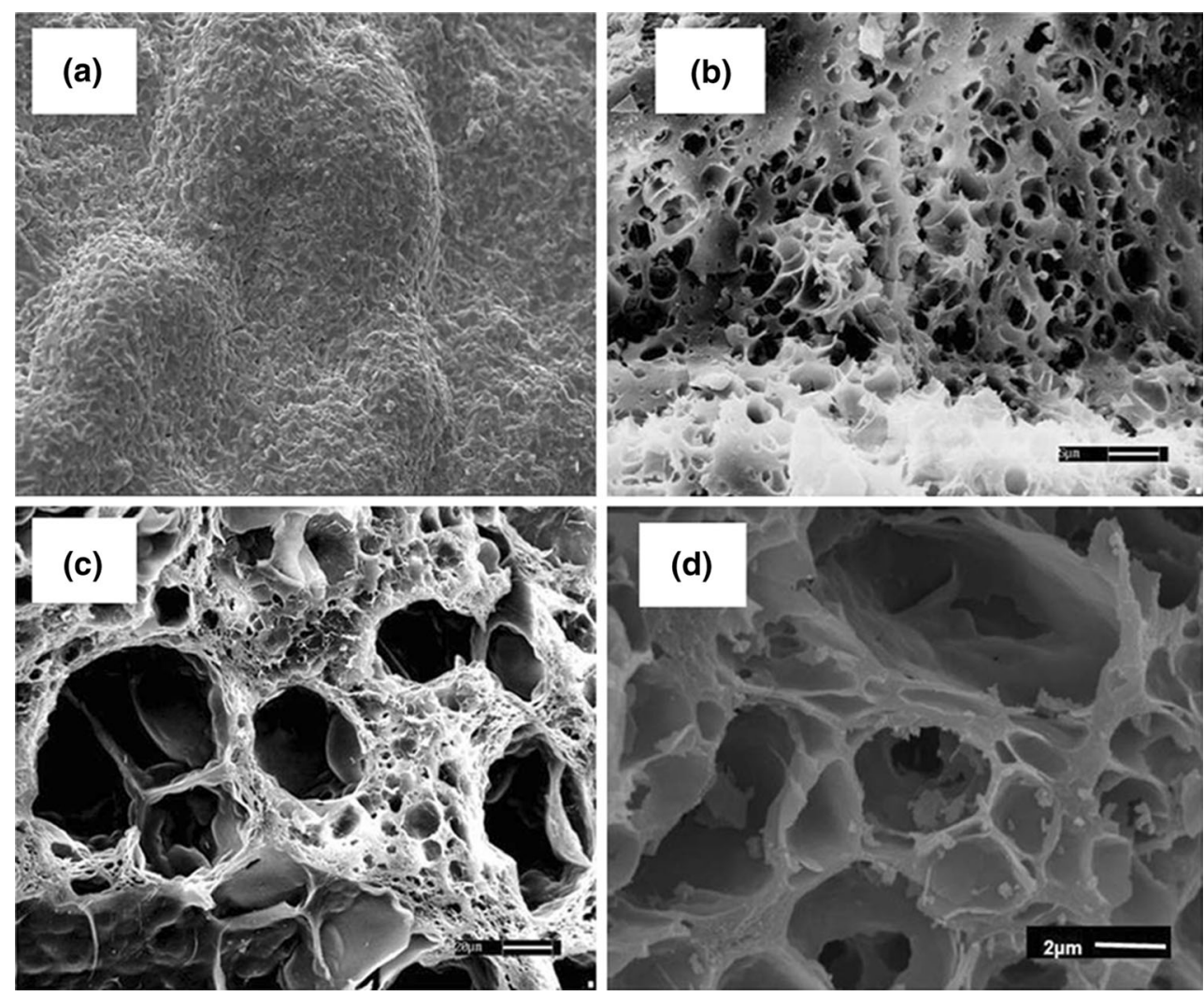

Fig. 2 SEM images of a adsorbent before calcination, b PA, c MIPA before As adsorption, d MIPA after As adsorption

structural integrity of alumina and magnesia after adsorption. Additional peaks at 61.4 and 62.4 might be due to the presence of adsorbed arsenate on the MIPA surface.

\section{FTIR analysis of adsorbent}

FTIR spectra of MIPA before and after calcinations and also after adsorption of arsenic are presented in Fig. S3. The band at $3400 \mathrm{~cm}^{-1}$ in MIPA before calcinations (Fig. S3a) corresponded to $-\mathrm{OH}$ stretching vibration due to the presence of chitosan template. After calcinations, this peak almost disappeared due to degradation of chitosan. FTIR spectrum of MIPA before adsorption showed major peaks at around 3400 and $1636 \mathrm{~cm}^{-1}$ due to the stretching vibration of hydroxyl groups $(-\mathrm{OH})$ and bending vibration of water molecules, respectively (Fig. S3b). After adsorption, the peak shifted to $3420 \mathrm{~cm}^{-1}$ with some decrease in intensity, indicating the involvement of $-\mathrm{OH}$ in the arsenic adsorption, and it indicated the existence of $\mathrm{H}$-bonding formed by $\mathrm{OH} \cdots$ As (Fig. S3c). The bands from 1400 to $1600 \mathrm{~cm}^{-1}$ indicated the formation of alumina. The wellexpressed bands centered around 845 and $1459 \mathrm{~cm}^{-1}$ in the spectra of the samples after adsorption could be attributed to characteristic vibrations of $\mathrm{As}-\mathrm{O}$ in $\mathrm{H}_{2} \mathrm{AsO}_{4}{ }^{-}$. The results implied existence of arsenic species and its interaction with MIPA via Vander Waals force.

\section{Determination of adsorption capacity of MIPA}

Experiments were carried out to find individual adsorption capacity. Table S1 in supplementary material gives the capacities. It could be seen that the mesoporous adsorbent (MIPA) exhibited highest adsorption capacity.

\section{Effect of $p H$ and zeta potential}

The most important parameter influencing the adsorption capacity is the $\mathrm{pH}$ of adsorption medium. Arsenic is sensitive to $\mathrm{pH}$ in ground waters $(\mathrm{pH}$ 6.5-8.5) under oxidizing and reducing conditions. Redox potential (Eh) and $\mathrm{pH}$ are the most important factors controlling arsenic speciation. Under oxidizing conditions, $\mathrm{H}_{2} \mathrm{AsO}_{4}{ }^{-}$is dominant at low $\mathrm{pH}$ (less than about $\mathrm{pH}$ 6.9), while at higher $\mathrm{pH}, \mathrm{HAsO}_{4}{ }^{2-}$ becomes dominant $\left(\mathrm{H}_{3} \mathrm{AsO}_{4}^{0}\right.$ and $\mathrm{AsO}_{4}{ }^{3-}$ may be present in extremely acidic and alkaline conditions, respectively). Under reducing conditions at $\mathrm{pH}$ less than about $\mathrm{pH}$ 9.2, the uncharged arsenite species $\mathrm{H}_{3} \mathrm{AsO}_{3}^{0}$ predominates.

The distributions of the species as a function of $\mathrm{pH}$ are presented in Fig. S4 (supplementary material). In practice, most studies in the literature report speciation data without consideration of the degree of protonation. In the presence of extremely high concentrations of reduced sulfur, dissolved arsenic-sulfide species can be significant. Reducing, acidic 
conditions favor precipitation of orpiment $\left(\mathrm{As}_{2} \mathrm{~S}_{3}\right)$, realgar (AsS) or other sulfide minerals containing co-precipitated arsenic. Therefore, high-arsenic waters are not expected where there is a high concentration of free sulfide. Thio arsenite species will be more important at neutral and alkaline $\mathrm{pH}$ in the presence of very high sulfide concentrations.

It was well documented that the surface functional groups of adsorbents together with the forms of arsenic species (adsorbates) are strongly $\mathrm{pH}$ dependent.

The dissociation reaction of arsenic acid (arsenate) is shown below

$$
\begin{aligned}
& \mathrm{H}_{3} \mathrm{AsO}_{4}+\mathrm{H}_{2} \mathrm{O} \leftrightarrow \mathrm{H}_{2} \mathrm{AsO}_{4}^{-}+\mathrm{H}_{3} \mathrm{O}^{+}(\mathrm{pK} \text { a } 2.2) \\
& \mathrm{H}_{2} \mathrm{AsO}_{4}^{-}+\mathrm{H}_{2} \mathrm{O} \leftrightarrow \mathrm{HAsO}_{4}^{2-}+\mathrm{H}_{3} \mathrm{O}^{+}(\mathrm{p} K \mathrm{a} \text { 7.0) } \\
& \mathrm{HAsO}_{4}^{2-}+\mathrm{H}_{2} \mathrm{O} \leftrightarrow \mathrm{AsO}_{4}^{3-}+\mathrm{H}_{3} \mathrm{O}^{+}(\mathrm{p} K \mathrm{a} \text { 11.5) }
\end{aligned}
$$

The dissociation constants $(\mathrm{pKa}$ ) approximate the $\mathrm{pH}$ at which equal quantities of each form of arsenic are present. At a pH level, one unit less than the $\mathrm{pKa}$, approximately $90 \%$ of the arsenic, is in the form on the left side of the reaction. The converse is true for $\mathrm{pH}$ levels higher than the $\mathrm{pKa}$ value. Thus, $\mathrm{As}(\mathrm{V})$ ion occurs mainly in the form of $\mathrm{H}_{2} \mathrm{AsO}_{4}{ }^{-}$in the $\mathrm{pH}$ range between 3 and 6 , while a divalent anion $\mathrm{HAsO}_{4}{ }^{2-}$ dominates at higher $\mathrm{pH}$ values (such as between $\mathrm{pH} 8$ and $\mathrm{pH}$ 10.5). In the intermediate region (i.e., in the $\mathrm{pH}$ range between 6 and 8), both species coexist with one another, which contribute negative charge on the surface.

The effect of the $\mathrm{pH}$ on the adsorption of $\mathrm{As}(\mathrm{V})$ of initial concentration $20 \mathrm{mg} / \mathrm{L}$ onto porous adsorbent was studied in the $\mathrm{pH}$ range 3-11 (Fig. 3). It was observed that adsorption of $\mathrm{As}(\mathrm{V})$ increased rapidly with increasing $\mathrm{pH}$ and attained maximum $(95 \%)$ at $\mathrm{pH} 7.5$ and thereafter dropped significantly at higher $\mathrm{pH}$ values, e.g., $16 \%$ at $\mathrm{pH} 11$. The zeta potential was measured as a function of $\mathrm{pH}$ in the range 4-11 since the isoelectric point (IEP) or point of zero

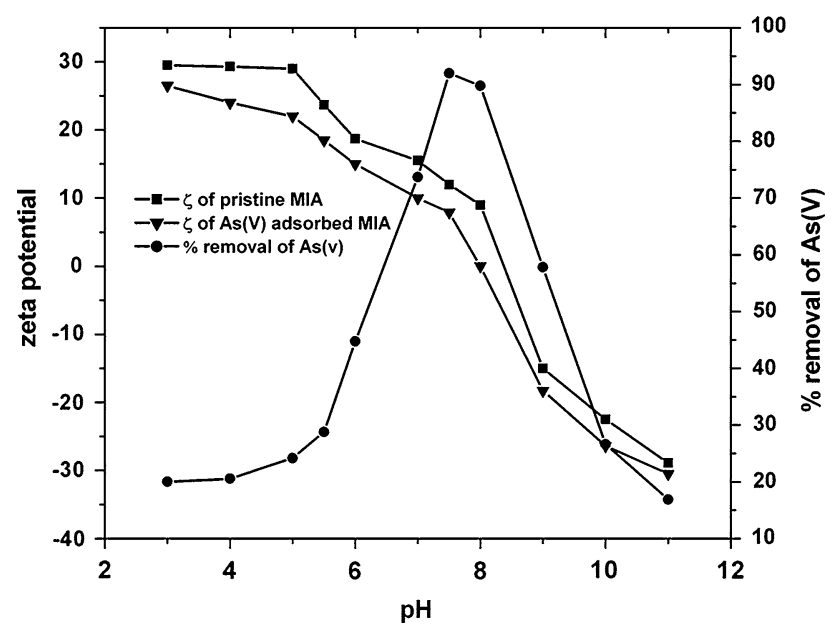

Fig. 3 Effect of $\mathrm{pH}$ and zeta potential on $\mathrm{As}(\mathrm{V})$ adsorption by MIPA at $303 \mathrm{~K}$ charge could predict MIPA surface charge $(+$ or -$)$ at operating pH. It could be seen from Fig. 3 that IEP of MIPA before and after arsenic adsorption was $\mathrm{pH} 8.5$ and 8 , respectively. In the $\mathrm{pH}$ range $4-8$, arsenic predominantly exists as anionic $\mathrm{H}_{2} \mathrm{AsO}_{4}{ }^{-}$and $\mathrm{HAsO}_{4}{ }^{2-}$ species, which contribute negative charge on the surface (Xu et al. 2002; Lin and Wu 2001). Thus, shift of IEP after the adsorption to a lower $\mathrm{pH}$ value was due to the formation of negatively charged surface complexes by specific adsorption of arsenate onto MIPA. Further, it could also be implied that the adsorption of arsenate onto MIPA was through innersphere complexes since no specific chemical reaction occurred between the adsorbate and the outer surface in the outer sphere. The maximum arsenic removal at $\mathrm{pH} 7.5$ could be explained by the fact that MIPA surface possessed a net positive charge at $\mathrm{pH}$ below 8.5 , and hence, the possibility of electrostatic repulsion did not exist. A progressive decrease in arsenic removal was observed with increase in $\mathrm{pH}$. This could be attributed to the competition for the active sites by $\mathrm{OH}-$ ions and the electrostatic repulsion of arsenate ions by the negatively charged MIPA surface. It is clear that the presence of arsenate anions made the adsorbent surface more negatively charged at higher $\mathrm{pH}$. Thus, specific adsorption rather than a purely electrostatic interaction could be predicted from the drop of isoelectric point.

\section{Effect of doses of adsorbent and adsorption isotherm}

The effect of adsorbent dose on percentage removal of $\mathrm{As}(\mathrm{V})$ is illustrated in Fig. S5 (supplementary material). The figure reveals that uptake of $\mathrm{As}(\mathrm{V})$ increased rapidly from 0.1 to $0.5 \mathrm{~g}$ and marginally thereafter. The initial increase in the efficiency of removal from 45 to $95 \%$ may be attributed to the fact that more surface area is available for arsenic to be adsorbed with increase in adsorbent dose. Further increment in adsorbent does not affect much due to non-availability of adsorbate for a given initial concentration of arsenic. In the subsequent studies, the adsorbent dose selected was $0.5 \mathrm{~g}$.

To address the equilibrium adsorption, various isotherms were used, e.g., Langmuir, Freundlich. The isotherm data (Table S2, supplementary material) suggested that the adsorption of arsenic could not be modeled perfectly by the Langmuir isotherm, whereas equilibrium data fitted very well with Freundlich isotherm, suggesting a heterogeneous adsorption (plots shown in supplementary material, Fig. S6).

\section{Adsorption kinetics}

In order to investigate the adsorption mechanism of $\mathrm{As}(\mathrm{V})$ on porous adsorbent, the experimental data were analyzed, 
Fig. 4 a Pseudo-first-order, b pseudo-second-order kinetics for $\mathrm{As}(\mathrm{V})$ adsorption, $\mathbf{c}$ intraparticle pore diffusion, d particle diffusion for $\mathrm{As}(\mathrm{V})$ adsorption

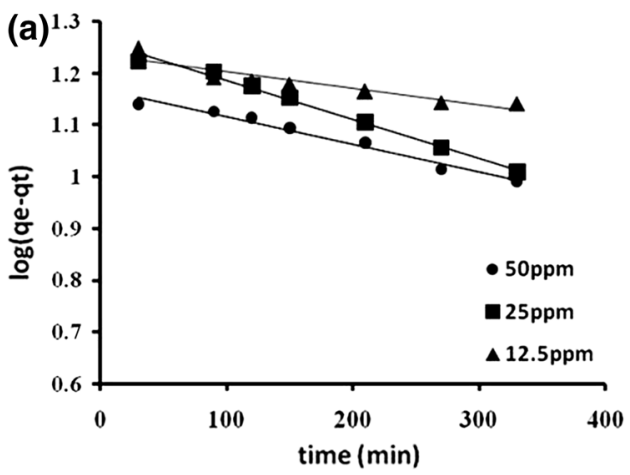

(c)

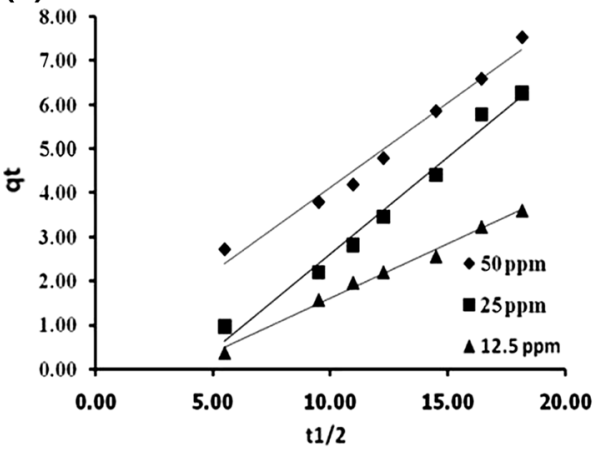

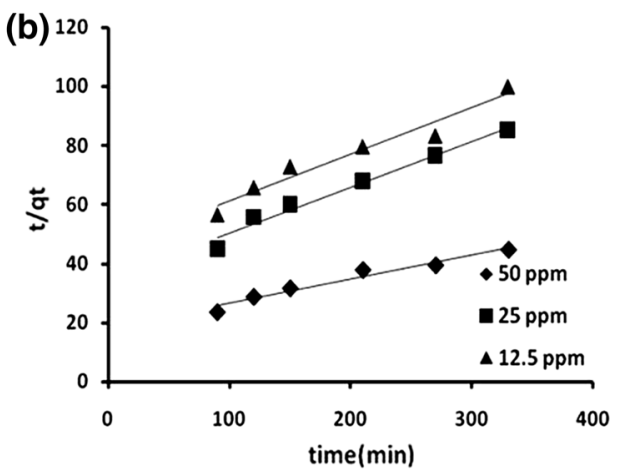

(d)

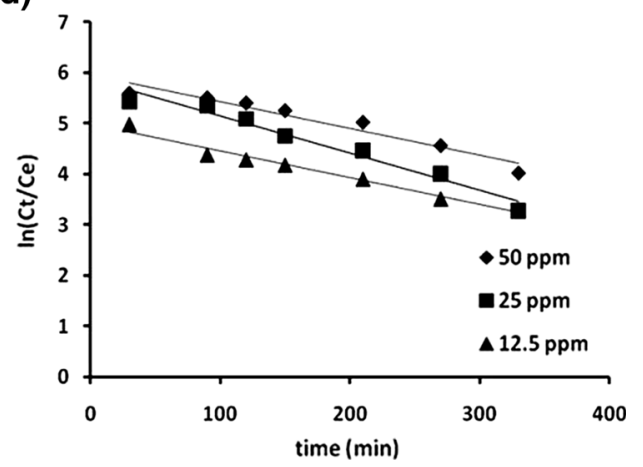

employing pseudo-first-order, pseudo-second-order and intra-particle diffusion kinetic models at different initial concentration of $\mathrm{As}(\mathrm{V})$. The uptake of $\mathrm{As}(\mathrm{V})$ onto the adsorbent was studied at different time intervals. Adsorption of arsenic increased with time, and it was fast in the first 10-60 min, whereas the adsorption rate slowed down and attained equilibrium at $5 \mathrm{~h}$. This value was determined by the measurement of the arsenic concentration at regular intervals until the concentration reached a constant value. A maximum of $98 \%$ arsenic was adsorbed in $5 \mathrm{~h}$. The probable reaction kinetics models depicting pseudo-first order and pseudo-second order were investigated with the adsorption data obtained from the adsorption of arsenic at different time intervals. Pseudo-first-order rate expression of Lagergren equation (Bansiwal et al. 2010) is given as

$\mathrm{d} q_{\mathrm{t}} / \mathrm{d} t=k_{1}\left(q_{\mathrm{e}}-q_{\mathrm{t}}\right)$

The integrated and logarithmic form of the above equation is written as

$\log \left(q_{\mathrm{e}}-q_{\mathrm{t}}\right)=\log q_{\mathrm{e}}-k_{1} t$

where $q_{\mathrm{e}}$ and $q_{t}$ are the amount of arsenic adsorbed on the adsorbent at equilibrium $(\mathrm{mg} / \mathrm{g})$ and at time $t(\mathrm{~min})$, respectively, and $k_{1}$ is the rate constant of the pseudo-firstorder adsorption $\left(\mathrm{min}^{-1}\right)$. The adsorption rate constant was determined from the slope of the linear plot of $\log \left(q_{\mathrm{e}}-q_{t}\right)$ versus $t$ (Fig. 4a). The pseudo-second-order rate expression is as follows: $\mathrm{d} q_{\mathrm{t}} / \mathrm{d} t=k_{2}\left(q_{\mathrm{e}}-q_{\mathrm{t}}\right)^{2}$

Integrated and rearranged form of this equation is

$t / q_{\mathrm{t}}=1 / k_{2} q_{\mathrm{e}}^{2}+t / q_{\mathrm{e}}$

where $k_{2}$ is the pseudo-second-order rate constant $(\mathrm{g} / \mathrm{mg} /$ $\mathrm{min}$ ). This was calculated from the slope and intercept of the plot $t / q_{t}$ versus $t$ (Fig. 4b). The rate constants obtained from first- and second-order pseudo-kinetic models are presented in Table S3 (Supplementary material). The larger the $k_{1}$ value, the quicker is the adsorption rate, whereas the lesser $k_{2}$ value represents the faster adsorption rate (Shihabudheen et al. 2006). The value of $k_{1}$ and $R^{2}$ obtained from Fig. 4a did not fit well with the first-order rate model (Eq. 3). However, the values of low $k_{2}$ and $R^{2}$ obtained from Fig. 4b suggested pseudo-second-order model (Eq. 5). The well-fitted pseudo-second-order kinetic model predicted a chemisorptions process involving ion exchange (Ho 2006).

In spite of adsorption occurring on the surface of adsorbent, the adsorbate molecules might also diffuse into the interior of the pores of the adsorbent. Thus, sorption could also be modeled by pore diffusion or particle diffusion model (Fig. 4c, d). The existence of intra-particle diffusion in the adsorption process may be determined from the following equation (Namasivayam and Yamuna 1995):

$q_{\mathrm{t}}=k_{i} t^{1 / 2}$ 
where $k_{i}$ is the intra-particle diffusion rate constant $(\mathrm{mg} / \mathrm{g} /$ $\min ^{1 / 2}$ ). Figure $4 \mathrm{c}$ shows a plot of the amount of arsenic adsorbed $\left(q_{t}\right)$ versus the square root of time $\left(t^{-1 / 2}\right)$. The correlation of the above variables was a straight line, which did not pass through the origin. This suggested that the presence of intra-particle diffusion might not be important in the whole adsorption process. The surface adsorption might be the predominant mechanism of arsenic uptake instead. This unusual behavior might be due to the heterogeneous nature of MIPA surface. Therefore, the adsorption of arsenic onto MIPA could be explained by both the effects, e.g., surface adsorption and intra-particle diffusion.

Again, the diffusion through individual particles, i.e., inter-particle diffusion model can be written as:

$\ln \left(C_{\mathrm{t}} / C_{\mathrm{e}}\right)=-k_{\mathrm{p}} t$

The value of $k_{\mathrm{p}}\left(\mathrm{min}^{-1}\right)$, particle diffusion coefficient, was obtained by slope of the plot between $\ln \left(C_{\mathrm{t}}\right)$ and $t$ (shown in Table S3).

\section{Adsorption thermodynamics}

Thermodynamic parameters of adsorption namely standard free energy change $(\Delta G)$, enthalpy change $(\Delta H)$ and entropy change $(\Delta S)$ were calculated using thermodynamic equations (Eqs. 8,9$)$. Standard free energy change $(\Delta G)$ is given by the equation

$\Delta G^{0}=-R T \ln K$

where $\Delta G^{0}$ is the standard free energy change of sorption $\left(\mathrm{kJ} \mathrm{mol}^{-1}\right), T$ the temperature in $\mathrm{K}, R$ the universal gas constant $(8.314 \mathrm{~J} / \mathrm{mol} / \mathrm{K})$, and $K$ is the sorption equilibrium constant determined from the slope of $\ln \left(q_{\mathrm{e}} / C_{\mathrm{e}}\right)$ against $C_{\mathrm{e}}$ at different temperatures. The standard enthalpy change $(\Delta H)$ and standard entropy change $(\Delta S)$ were calculated using following Vant Hoff's equation (Khan and Singh 1987; Singh and Pant 2004)

$\ln k_{\mathrm{o}}=\Delta H^{0} / R T+\Delta S^{0} / R$

where $\left(\Delta H^{0}\right)$ is standard enthalpy change $(\mathrm{kJ} / \mathrm{mol})$ and $\left(\Delta S^{0}\right)$ is standard entropy change $(\mathrm{KJ} / \mathrm{mol} / \mathrm{K})$. The values of $\Delta H$ and $\Delta S$ were obtained from the slope and intercept of the Vant Hoff's plot of lnk against 1/T shown in Fig. S7 (Supplementary material). These were evaluated as $-56.252 \mathrm{~kJ} / \mathrm{mol}$ and $0.1726 \mathrm{~kJ} / \mathrm{mol} / \mathrm{K}$, respectively. The negative value of $\Delta H$ indicated the exothermic nature of the sorption process. $\Delta S$ was considered as a measure of randomness at the solid/liquid interface during arsenic sorption, and the positive value suggested the sorption process as irreversible and stable. The negative values of $\Delta G$ obtained at all temperatures of the study indicated feasibility and spontaneity of the sorption reaction.
Positive entropy change (entropy system + entropy surroundings) indicated that the reaction was spontaneous as the system becomes more disordered. In the adsorption of arsenic $(\mathrm{V})$, positive values of $\Delta S^{\circ}$ indicated increased randomness of the solid/solution interface. In presence of aqueous medium, mixed oxide of MIPA, i.e., $\mathrm{Al}_{2} \mathrm{O}_{3}$ and $\mathrm{MgO}$ forms hydroxide that leads to structural disorder by ligand exchange with arsenate ions. During adsorption the adsorbed water molecules which was displaced by the adsorbate, As $(\mathrm{V})$ suggests some structural changes in adsorbate and adsorbent interface. This allowed the prevalence of randomness in the system.

Again, adsorption involves attracting $\mathrm{As}(\mathrm{V})$ molecules on surface of the adsorbent. Due to this, energy was released, and thus, heat of adsorption was negative. The large negative value of enthalpy was due to combined effect of physical and ligand exchange process in the said adsorption. This was also supported by FTIR data.

\section{Mechanism of adsorption}

Arsenic removal by MIPA appeared to be governed by both physical adsorption and ligand exchange mechanisms. As stated earlier, the arsenate ions on the oxide surface formed coordination shells with $\mathrm{OH}$ groups through acceptance or release of $\mathrm{H}^{+}$at various $\mathrm{pH}$, resulting in the development of a surface charge. In acidic medium, the concentration of $\mathrm{H}^{+}$ion remained high, and thus, MIPA surface acquired positive charge, which adsorbed arsenate ions. This nature of attractive force between MIPA and As $(\mathrm{V})$ ions was confirmed by the FTIR results due to the appearance of new peak at $845 \mathrm{~cm}^{-1}$, the characteristic of $\mathrm{O}-\mathrm{H} \cdots$ As vibration band on the arsenic-loaded MIPA. With increase in $\mathrm{pH}$, the surface slowly acquired negative charges, which repelled arsenate ions, and hence, arsenic removal by the electrostatic attraction in alkaline medium was ruled out. In addition, ligand exchange mechanism was also involved in arsenic removal by MIPA. The $\mathrm{OH}$ group present on the MIPA surface was considered as the charge carrier, which underwent exchange with arsenate ions from water. This was also confirmed by the appearance of a broad peak at $3420 \mathrm{~cm}^{-1}$ in FTIR analysis. The stepwise mechanisms of hydration of oxides, H-bonding and ligand exchange were shown in scheme S1 (Supplementary material).

\section{Packed bed column study}

Column study is essential for the design of industrial-scale fixed-bed absorber systems (Abhijit et al. 2008; Kundu and Gupta 2005). The experiment was conducted to evaluate the effects of various process parameters such as the initial $\mathrm{As}(\mathrm{V})$ concentration, the bed depth and the inlet flow rate 
on removal of arsenic. The point on the dynamic removal curve (Fig. 5) at which arsenic concentration reached its maximum permissible value $(0.01 \mathrm{mg} / \mathrm{L})$ was referred to as the breakthrough point. The point where the effluent arsenic concentration reached $90 \%$ of the influent value $(0.3 \mathrm{mg} / \mathrm{L})$ was considered as the point of column exhaustion.

\section{Effect of flow rate}

The effect of flow rate on $\mathrm{As}(\mathrm{V})$ adsorption was investigated by varying the flow rate from 6 to $20 \mathrm{~mL} / \mathrm{min}$ with initial As(V) concentration of $(300 \mu \mathrm{g} / \mathrm{L}), 10-\mathrm{cm}$ bed depth and column diameter of $1.5 \mathrm{~cm}$. The effect of flow rate on breakthrough performance is depicted in Fig. 5a. The experimental breakthrough time $\left(t_{\mathrm{b}}\right.$, corresponding to effluent concentration of $0.01 \mathrm{mg} / \mathrm{L}$ ) for flow rates 6,10 and $20 \mathrm{~mL} / \mathrm{min}$ was found to be 100,85 and $42 \mathrm{~h}$, respectively (Fig. 5a). The exhaust time ( $t_{\mathrm{e}}$, corresponding to effluent concentration of $90 \%$ of influent concentration) for flow rates 6,10 and $20 \mathrm{~mL} / \mathrm{min}$ was observed as 180 and 160 , $100 \mathrm{~h}$, respectively. At lower flow rates, the adsorbate had more time to bond with the adsorbent, whereas higher flow rates caused reduced contact time and hence poor distribution of the liquid inside the column leading to a lower diffusivity of the adsorbate through the adsorbent particles. The sorption data were evaluated, and total amount of arsenic passed through the column $\left(m_{\text {tot }}\right)$, amount of As

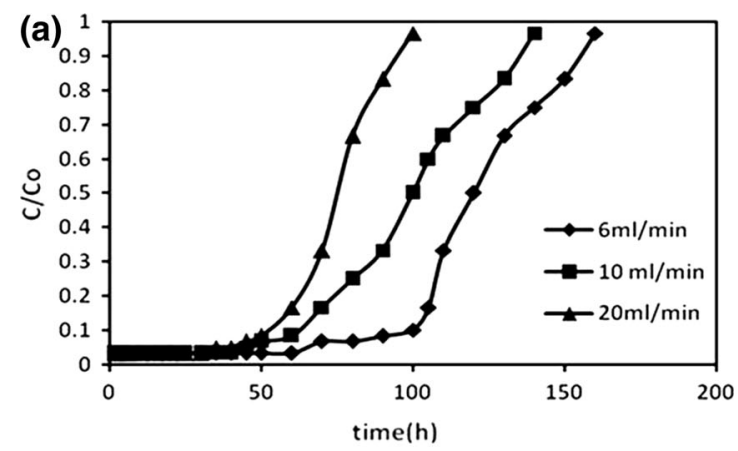

adsorbed $\left(q_{\text {tot }}\right)$, total removal percentage of As, time to achieve breakthrough and exhaustion time at different flow rates are presented in Table S4.

\section{Effect of bed depth}

Water containing $300 \mu \mathrm{g} / \mathrm{L}$ of $\mathrm{As}(\mathrm{V})$ was passed through the adsorption columns at $10 \mathrm{~mL} / \mathrm{min}$ to study effect of bed height. Figure $5 \mathrm{~b}$ represents the performance of breakthrough curves for bed heights of 4,6 and $10 \mathrm{~cm}$. With increase in bed height, the throughput volume increased due to higher contact time and availability of more binding sites for the sorption. At a relatively lower contact time, the curve was steeper showing faster exhaustion of the bed. The total As(V) adsorption was found to be 16.96, 22.86 and $35.91 \mathrm{mg}$ with bed height of 4,6 and $10 \mathrm{~cm}$, respectively, and the corresponding total amount of As(V) passed through the column was $21.6,27$ and $36 \mathrm{mg}$. The breakthrough time increased with increase in bed depth, suggesting it to be an important parameter. The larger the breakthrough time, the better was the intra-particulate mass transfer phenomena.

\section{BDST model}

Bed depth service time approach was used to predict the maximum adsorption capacity. It is generally accepted that the BDST model offers the simplest approach and rapid

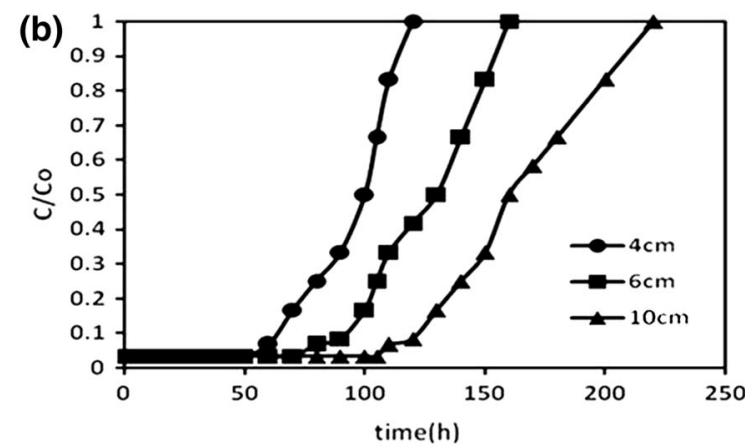

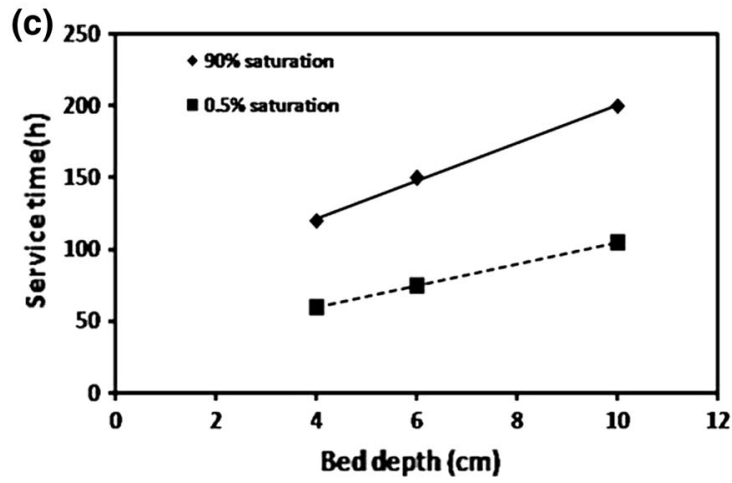

Fig. 5 Breakthrough curve of As adsorption onto MIPA at a different flow rate, $\mathbf{b}$ different bed height, $\mathbf{c}$ bed depth versus service time plot of BDST model at 0.5 and $90 \%$ saturation of MIPA fixed bed, flow rate $10 \mathrm{~mL} / \mathrm{min}$ 
prediction of adsorber design and performance (Han et al. 2007; Abhijit et al. 2010). This model is based on the assumption that forces like intra-particle diffusion and external mass transfer resistance are negligible and that the adsorption kinetics is controlled by surface chemical reaction between the solute in the solution and the unused adsorbent.

The critical bed depth $\left(X_{\mathrm{o}}\right)$ represents the theoretical depth of adsorbent, which is necessary to keep the concentration below threshold concentration, $C_{\mathrm{B}}$. The estimation of the characteristic parameters such as the maximum adsorption capacity $N_{\mathrm{o}}$, adsorption rate constant $K$ and $X_{\mathrm{o}}$ was done using the following relation assuming that the adsorption rate was proportional to residual capacity of the sorbent and the concentration of the sorbing species.

$t=N_{\mathrm{o}} x / C_{\mathrm{o}} V-1 / C_{\mathrm{o}} K \ln \left(C_{\mathrm{o}} / C_{\mathrm{B}}-1\right)$

where $C_{\mathrm{o}}=$ initial solute concentration $(\mathrm{mg} / \mathrm{L}) ; C_{\mathrm{B}}=$ desired solute concentration at breakthrough $(\mathrm{mg} / \mathrm{L}) ; x=$ bed depth $(\mathrm{cm}) ; V=$ linear flow velocity of feed to bed $(\mathrm{cm} / \mathrm{h})$; and $t=$ service time of column.

This equation is of the form:

$t=a x-b$

where slope, $a=N_{\mathrm{o}} / C_{\mathrm{o}} V$; intercept, $b=1 / K C_{\mathrm{o}} \ln \left(C_{\mathrm{o}} /\right.$ $C_{\mathrm{B}}-1$ ); $t$ versus $x$ was plotted (Fig. 5c) for the breakthrough, i.e., $0.5 \%$ saturation and exhaust, i.e., $90 \%$ saturation. The corresponding equations are as follows:

$t=13.21 x+68.57$ for $90 \%$ saturation

$t=7.5 x+30$ for $0.5 \%$ saturation

Setting $t=0$ in Eq. 12, the minimum column height $\left(x_{0}\right)$ necessary to produce an effluent concentration $C_{\mathrm{B}}$ was calculated. From the slope and intercept of Fig. $5 \mathrm{c}$ and Eq. 12 , the design parameters $K, N_{\mathrm{o}}$ and $x_{0}$ were evaluated as $0.1166 \mathrm{~L} / \mathrm{mg}$ h, $1346.21 \mathrm{mg} / \mathrm{L}$ and $5.18 \mathrm{~cm}$, respectively.

With the increase in bed depth, the residence time of the fluid inside the column increased, allowing the adsorbate molecules to diffuse deeper inside the adsorbent. With a higher $K$, even a short bed would avoid early breakthrough, but with decrease in $K$ a progressively higher volume bed was required to avoid breakthrough. The linear equation produced a $R^{2}$ value of 0.99 , which indicated the validity of the BDST model. The advantage of the BDST model was that any experimental test could reliably be scaled up to higher flow rates without further experimental runs.

\section{Statistical design of experiments}

Factorial designs allow the simultaneous study of the effects that several factors may have on the optimization of a particular process (Hasan et al. 2009; Box et al. 1978). The effects are the differential quantities expressing how a response changes with one or more factors.

Different process parameters such as flow rate $\left(x_{1}\right)$, bed height $\left(x_{2}\right)$ and initial concentration $\left(x_{3}\right)$ of $\operatorname{As}(\mathrm{V})$ were considered as variables for the designing of experimental matrix. Each factor was studied at two levels, "low" $(-1)$ and "high" $(+)$. The response was expressed as the removal percentage $(\% R)$ of $\mathrm{As}(\mathrm{V})$. A $2^{3}$ complete factorial design was performed with the values of the operating variables shown in Table 2 . The outcome was 8 tests with all possible combinations of $x_{1}, x_{2}$ and $x_{3}$. The percentage removal was measured in each of these tests. The complete factorial model that was used to fit the data in Table 1 was

$$
\begin{aligned}
E(Y)= & \beta_{0}+\beta_{1} X_{1}+\beta_{2} X_{2}+\beta_{3} X 3+\beta_{12} X_{1} X_{2}+\beta_{13} X_{1} X_{3} \\
& +\beta_{23} X_{2} X_{3}+\beta_{123} X_{1} X_{2} X_{3}
\end{aligned}
$$

where the parameters $\beta_{i}$ are responsible for the influence of the operating variable $X_{i}$ on the response $Y$, while $\beta_{i j k}$ are responsible for possible interactions among the operating variables $i, j$ and $k$ and the effect of this interaction on the response. Values of the parameter displayed in Eq. (14) were obtained from the least square estimates:

$\beta=\left(X^{\mathrm{T}} X\right)^{-1} X^{\mathrm{T}} Y$

Using the experimental data listed in Table 2, the matrix was evaluated, and accordingly, the parameters in Eq. 14
Table 2 Experimental factorial design for $(\%)$ As removal

\begin{tabular}{llrll}
\hline Run & \multicolumn{2}{l}{ Main operating factors } & & $\begin{array}{l}\text { Response } \\
\text { nyynn}\end{array}$ \\
\cline { 2 - 4 }$X_{1}$ : flow rate $(\mathrm{mL} / \mathrm{min})$ & $X_{2}$ : bed height $(\mathrm{cm})$ & $X_{3}$ : initial conc $(\mu \mathrm{g} / \mathrm{L})$ & $\%$ removal of As $(\mathrm{V})$ \\
\hline 1 & 1 & -1 & 1 & 32 \\
2 & 1 & -1 & -1 & 52 \\
3 & -1 & 1 & 1 & 88 \\
4 & -1 & 1 & -1 & 92 \\
5 & -1 & -1 & -1 & 72 \\
6 & 1 & 1 & -1 & 58 \\
7 & 1 & 1 & 1 & 43 \\
8 & -1 & -1 & 1 & 65 \\
\hline
\end{tabular}


were estimated and results are presented in Table S5. Based on $F$ test and Student's $t$ test, some effects were discarded, because these did not exhibit any statistical significance. Resultant model was represented by

$Y=62.75-16.5 X_{1}+7.50 X_{2}-5.75 X_{3}-3.25 X_{1} X_{2}$

The model $F$ value of 27.74 implied that the model was significant. There was only a $1.05 \%$ chance that this large model $F$ value occured due to noise. Values of "Prob $>F$ " less than 0.0500 indicated that the model terms were significant. The statistical significance of the factors and their interaction on the response were evaluated by Pareto diagram (Fig. S8). This diagram predicted $X_{1}$ (flow rate) and $X_{2}$ (bed height) to be significant model terms. Values greater than 0.10 indicate that the model terms are not significant. A student's $t$ test was performed to determine whether the calculated effects were significantly different from zero; these values for each effect are shown in the Pareto chart by vertical columns. A $t$ value of 4.3 signifies $95 \%$ confidence level. As shown in Fig. S8, the effect $\mathrm{X}_{1} \mathrm{X}_{3}$ was positioned around a reference line, whereas $X_{2} X_{3}$ and $X_{1} X_{2} X_{3}$ were far below the reference lines, so these are not significant factors. The values that exceed a reference line, i.e., those corresponding to the $95 \%$ confidence interval, are significant values. According to Fig. 2, the main factors $\left(X_{1}, X_{2}\right.$ and $\left.X_{3}\right)$ and their interactions $\left(X_{1} X_{2}\right)$ that extended beyond the reference line were the only significant factors in arsenic removal.

The "Pred $R^{2}$ " of 0.8128 was in reasonable agreement with the "Adj $R^{2}$ " of 0.9386 (data shown in Table S6). "Adeq Precision" measures the signal-to-noise ratio. A ratio greater than 4 is generally desirable. Thus, a ratio is 14.529, which indicated an adequate signal. This model might be used to navigate the design space.

Table 3 shows that the difference between the measured and the predicted values did not exceed $5 \%$ except the run 1 and 2. Therefore, all these results indicated that the model was suitable to address data adequately. From Eq. 15, column bed height $\left(X_{2}\right)$ showed the strongest effect on the response since coefficient of $X_{2}\left(b_{2}=+7.5\right)$ was larger than the coefficients of the other investigated factors; the positive sign indicated that there was a direct relation between the two.

\section{Interaction effect}

The main effects of factors ( $X_{1}$ : flow rate, $X_{2}$ : bed height, $X_{3}$ : initial concentration of As) and the interaction between factors $\left(X_{1} X_{2}, X_{2} X_{3}, X_{1} X_{3}\right.$ and $\left.\mathrm{ABC}\right)$ were determined by ANOVA. An interaction is effective when the change in the response from low to high levels of a factor is
Table 3 Comparison between experimental and predicted value

\begin{tabular}{lllrc}
\hline Runs & Observed value & Predicted value & Residuals & \% error \\
\hline 1 & 32 & 36.25 & -4.25 & 13.28 \\
2 & 52 & 47.75 & 4.75 & 9.13 \\
3 & 88 & 84.25 & 3.75 & 4.26 \\
4 & 92 & 95.75 & -3.25 & 3.53 \\
5 & 72 & 74.25 & -2.25 & 3.12 \\
6 & 58 & 56.25 & 1.75 & 3.01 \\
7 & 43 & 44.75 & -1.75 & 4.06 \\
8 & 65 & 65.75 & -0.75 & 1.15 \\
\hline
\end{tabular}

dependent on the level of a second factor, i.e., when the lines do not run parallel.

Table S5 (supplementary material) displays the main factors' effect, factors' interaction effect, coefficients of the model, standard deviation of each coefficient and the probability for the full $2^{3}$ factorial design. Figure S9 illustrates the mutual interactive effects of the combination of independent variables on arsenic(V) adsorption capacity in the manner of linear and 3D surface plots. These plots clearly indicated that the interaction between bed height and flow rate $\left(X_{1} X_{2}\right)$ and $X_{1} X_{3}$ was the statistically significant factor, which was also shown by Pareto charts (Fig. S8).

\section{Regeneration study}

In order to reduce the cost and waste production, regeneration of any exhausted adsorbent is an important factor. In this study, $\mathrm{NaOH}$ solution (various concentrations, 0.05 , $0.1,0.25 \mathrm{M}$ ) was used as the eluent for arsenic desorption from exhausted sorbents. After $\mathrm{NaOH}$ treatment, the surface became more active due to increase in pores. The higher percentage of desorption indicated that ion exchange or physical interaction played significant role in the sorption process. To test the adsorption potential of regenerated MIPA, adsorption studies were carried out with an input of $300 \mu \mathrm{g} / \mathrm{L}$, and a small reduction $(\sim 5 \%)$ of removal efficiency up to five cycles.

\section{Comparison with other results and cost analysis}

Except a few studies on continuous operation, most of the research on arsenic removal considered batch operations. However, the data obtained under batch conditions are generally not applicable in industrial and household treatment systems. The efficiency of MIPA packed column for $\mathrm{As}(\mathrm{V})$ removal was compared with other adsorbents and shown in Table 4 . The running cost of column would be extremely low and estimated to be $\$ 2$ per $100 \mathrm{~kL}$ water processed. 
Table 4 Comparison of adsorption capacities of difference adsorbents for arsenic removal in column operation

\begin{tabular}{|c|c|c|c|c|c|}
\hline Serial no. & Adsorbent & Column condition & $\begin{array}{l}\text { Adsorption } \\
\text { capacity }(\mathrm{mg} / \mathrm{g})\end{array}$ & $\mathrm{pH}$ & References \\
\hline 1. & Iron oxide-impregnated activated alumina & Bed height $6 \mathrm{~cm}$, flow rate $0.016 \mathrm{~cm}^{3} / \mathrm{s}$ & - & 12 & 11 \\
\hline 2. & Iron oxide-coated sand & Flow rate $21.5 \mathrm{~mL} / \mathrm{min}$ & $\begin{array}{l}0.52 \\
42.6 \mu \mathrm{g} / \mathrm{g}\end{array}$ & 7.6 & 12 \\
\hline 3. & Anion exchange polymer resin and iron oxide & Flow rate $7.5 \mathrm{~mL} / \mathrm{min}$ & 3.229 & 7.5 & 13 \\
\hline 4. & Polymeric cation exchanger/ferric oxide & Bed height $40 \mathrm{~mm}$ & 4.2 & 7.2 & 14 \\
\hline 5. & Siderite-coated sand & Bed height $150 \mathrm{~mm}$, Flow rate $1.8 \mathrm{~mL} / \mathrm{min}$ & 1.09 & & 15 \\
\hline 6. & Activated alumina & Bed height $6 \mathrm{~cm}$, flow rate $0.016 \mathrm{~cm}^{3} / \mathrm{s}$ & 0.007 & 7.6 & 31 \\
\hline 7. & Natural laterite & Bed height $30 \mathrm{~cm}$, flow rate $5 \mathrm{~mL} / \mathrm{min}$ & 0.147 & 5.5 & 32 \\
\hline 8. & Iron oxide-coated cement & Bed height $10 \mathrm{~cm}$, flow rate, $8.5 \mathrm{~mL} / \mathrm{min}$ & $505.3 \mathrm{mg} / \mathrm{L}$ & 8 & 33 \\
\hline 9. & Acid-activated laterite & Bed height $20 \mathrm{~cm}$, flow rate $11 \mathrm{~mL} / \mathrm{min}$ & $628 \mathrm{mg} / \mathrm{L}$ & 6.2 & 35 \\
\hline 10. & Present study & Bed height $10 \mathrm{~cm}$, flow rate $10 \mathrm{~mL}$ min & 17.2 & 7.5 & \\
\hline
\end{tabular}

\section{Field study}

The MIPA packed column was also tested with field samples collected from Akrampur pilot plant. Barasat $\left(22.7200^{\circ} \mathrm{N}, 88.4800^{\circ} \mathrm{E}, 280 \mu \mathrm{g} / \mathrm{L}\right)$ was considered for the study of these real samples. The up-flow inlet rate was kept at $10 \mathrm{~mL} / \mathrm{min}$ in the MIPA packed $10-\mathrm{cm}$ bed depth column at a $\mathrm{pH}$ of 7.5. Table 5 lists the characteristics of the groundwater (before and after treatment with MIPA at breakthrough time) supplied by the NABL (National accreditation board for testing and calibration laboratories) accredited laboratory, Supertendence Pvt. Ltd, Kolkata, India. It was observed that adsorbent removed iron to a great extent in addition to arsenic. The $\mathrm{pH}$ of the effluent water remained almost same as in the influent water, suggesting no post-treatment. The most interesting observation made from the results was that the combined effects of chloride, sulfate, phosphate and fluoride present in the real sample water did not interfere the arsenic adsorption. Thus, the effluent water quality (Table 5) suggested that the treated contaminated water could be used for household purposes.

\section{Conclusion}

An extensive laboratory-scale investigation was carried out to evaluate the fixed-bed column performance by newly developed adsorbent MIPA with adsorption capacity $17.2 \mathrm{mg} / \mathrm{L}$ with different bed depths and column up-flow rates. The adsorption mechanism followed pseudo-second-order reaction kinetics. The BDST model was used in the analysis of column performance data, and the values of adsorption rate and adsorption capacity coefficients $(K$ and $N$ ) were evaluated as 0.1166 $\mathrm{L} / \mathrm{mg} \mathrm{h}$ and $1346.21 \mathrm{mg} / \mathrm{L}$, respectively. The constants
Table 5 Quality of the real arsenic-contaminated water (before and after treatment)

\begin{tabular}{lll}
\hline Parameter & Before treatment & After treatment \\
\hline $\mathrm{pH}$ & 6.9 & 6.9 \\
$\mathrm{As}(\mathrm{V})(\mathrm{mg} / \mathrm{L})$ & 280 & 15 \\
Turbidity $[\mathrm{NTU}]$ & 6.5 & 6.4 \\
$\mathrm{Fe}(\mathrm{mg} / \mathrm{L})$ & 5.2 & 0.3 \\
$\mathrm{Hardness}\left(\mathrm{as} \mathrm{CaCO}_{3}\right)$ & 150 & 140 \\
$\mathrm{Ca}(\mathrm{mg} / \mathrm{L})$ & 28 & 24 \\
$\mathrm{Mg}(\mathrm{mg} / \mathrm{L})$ & 19 & 19.4 \\
$\mathrm{Cl}(\mathrm{mg} / \mathrm{L})$ & 8 & 6 \\
$\mathrm{SO}{ }_{4}(\mathrm{mg} / \mathrm{L})$ & 1 & 0.66 \\
$\mathrm{PO}_{4}(\mathrm{mg} / \mathrm{L})$ & 0.26 & 0.007 \\
$\mathrm{~F}_{(\mathrm{mg} / \mathrm{L})}$ & 0.21 & 0.11 \\
$\mathrm{TDS}$ & 324 & 336 \\
\hline
\end{tabular}

obtained from this model were utilized for scaling up of the fixed-bed adsorption column. The regeneration and subsequent reuse of the adsorbent MIPA offered an economical approach for the removal of $\mathrm{As}(\mathrm{V})$ from water. The experimental results in this study were well simulated in the full-factorial design model. The quality of the effluent water was found to be safe for human consumption. The most important performance of this MIPA packed column (10-cm bed height, $12 \mathrm{~g}$ adsorbent) was its capacity, i.e., $\sim 140 \mathrm{~L}$ of arsenic-contaminated water per day (of $300 \mu \mathrm{g} / \mathrm{L}$ reduced to less than $10 \mu \mathrm{g} / \mathrm{L}$ ), suggesting that the adsorbent was ideal for household water filter in rural area without the requirement of power.

Acknowledgments The author (S.S.) is indebted to DST-INSPIRE (DST/Inspire fellowship/2011/166), New Delhi, for her fellowship. The authors acknowledge DST (Sensor-Hub) and CRNN, Kolkata, for providing assistance in characterization adsorbent. 


\section{References}

Abhijit M, Sunando DG, Jayant Kumar B, Sirshendu D (2008) Batch and column study: adsorption of arsenate using untreated laterite as adsorbent. Ind Eng Chem Res 47:1620-1629

Abhijit M, Jayanta Kumar B, Sirshendu D (2010) Removal of arsenic from synthetic and natural groundwater using acid-activated laterite. Environ Prog Sustain 29:457-470

Bansiwal A, Pillewan P, Biniwale R, Rayalu S (2010) Copper oxide incorporated mesoporous alumina for defluoridation of drinking water. Microporous Mesoporous Mater 129:54-61

Biati A, Khezri SM, Mohammadi Bidokhti A (2014) Determination of optimum exposure time and $\mathrm{pH}$ for dye adsorption using an adsorbent made of sewage sludge. Int $\mathrm{J}$ Environ Res 8:653-658

Bissen M, Frimmel FH (2003) Arsenic - a review. Part II: Oxidation of arsenic and its removal in water treatment. Acta Hydrochim Hydrobiol 31:97-107

Bohart GS, Adams EQ (1920) Some aspects of the behavior of charcoal with respect to chlorine. J Am Chem Soc 42:523-544

Boldaji MR, Nabizadeh R, Dehghani MH, Nada K, Mahvi AH (2010) Evaluating the performance of iron nanoparticle resin in removing arsenate from water. J Environ Sci Health A Toxic/ Hazard Subst Environ Eng 45:946-950

Box GEP, Hunter WG, Hunter JS (1978) Statistics for experimenters: an introduction to design, data analysis, and model building. Wiley, New York

Brunauer S, Deming L, Deming W, Teller E (1940) On a theory of the van der Waals adsorption of gases. JACS. 62:1720-1723

Das J, Sarkar P, Panda J, Pal P (2014) low cost field test kits for arsenic detection in water. J Environ Sci Health A 49:108-115

Donga H, Guanb X, Wanga D, Li C, Xue Y, Dou X (2011) A novel application of $\mathrm{H}_{2} \mathrm{O}_{2}-\mathrm{Fe}$ (II) process for arsenate removal from synthetic acid mine drainage (AMD) water. Chemosphere 85:1115-1121

Drewnowski J, Makinia J (2014) The role of biodegradable particulate and colloidal organic compounds in biological nutrient removal activated sludge systems. Int J Environ Sci Technol 11:1973-1988

Ghaedi M, Mortazavi K, Jamshidi M, Roosta M, Karami B (2012) Oxidized multiwalled carbon nanotubes modified with 2-(2hydroxy-5-nitrophenyl)-4,5-diphenyl imidazole for solid phase extraction and preconcentration of some metal ions. Toxicol Environ Chem 94:846-859

Ghaedi M, Niknam K, Zamani S, Roosta M, Soylak M (2013) Silica chemically bonded $N$-propyl kriptofix 21 and 22 with immobilized palladium nanoparticles for solid phase extraction and preconcentration of some metal ions. Mater Sci Eng C Mater Biol Appl 6:3180-3189

Ghaedi M, Pakniat M, Mahmoudi Z, Sahraei R, Daneshfar A (2014) Synthesis of nickel sulfide nanoparticles loaded on activated carbon as a novel adsorbent for the competitive removal of methylene blue and safranin-O. Spectrochim Acta A Mol Biomol Spectrose 123:402-409

Guo H, Stüben D, Berner Z (2007) Removal of arsenic from aqueous solution by natural siderite and hematite. Appl Geochem 22:1039-1051

Gupta VK, Pathania D, Singh P (2014) Pectin-cerium(IV) tungstate nanocomposite and its adsorptional activity for removal of methylene blue dye. Int J Environ Sci Technol 11:2015-2024

Han R, Wang YF, Yu WH, Zou WH, Shi H, Liu HM (2007) Biosorption of methylene blue from aqueous solution by rice husk in a fixed-bed column. J Hazard Mater 141:713-718
Hasan SH, Srivastavaa P, Talat M (2009) Biosorption of Pb(II) from water using biomass of Aeromonas hydrophila: central composite design for optimization of process variables. J Hazard Mater 168:1155-1162

Ho YS (2006) Review of second-order models for adsorption systems. J Hazard Mater 136:681-689

Khan AA, Singh RP (1987) Adsorption thermodynamics of carbo furan on $\mathrm{Sn}(\mathrm{IV})$ arsenosilicate in $\mathrm{H}^{+}, \mathrm{Na}^{+}$and $\mathrm{Ca}^{2+}$ forms. Colloids Surf 24:33-42

Kim Y, Kim C, Choi I, Rengaraj S, Yi J (2004) Arsenic removal using mesoporous alumina prepared via a templating method. Environ Sci Technol 38:924-931

Kundu S, Gupta AK (2005) Analysis and modeling of fixed bed column operations on $\mathrm{As}(\mathrm{V})$ removal by adsorption onto iron oxide-coated cement (IOCC). J Colloid Interface Sci 290:52-60

Kuriakose S, Singh TS, Pant KK (2004) Adsorption of As(III) from aqueous solution onto iron oxide impregnated activated alumina. Water Qual Res J Can 39:258-266

Lenoble V, Deluchat V, Serpaud B, Bollinger JC (2003) Arsenite oxidation and arsenate determination by the molybdene blue method. Talanta 61:267-276

Lin TF, Wu JK (2001) Adsorption of arsenite and arsenate within activated alumina grains: equilibrium and kinetics. Water Res 35:2049-2057

Matthew J, DeMarco AK, SenGupta JE (2003) Greenleaf, arsenic removal using a polymeric/inorganic hybrid sorbent. Water Res 37:164-176

Mohan D, Pittman CU Jr (2007) Arsenic removal from water/ wastewater using adsorbents - a critical review. J Hazard Mater 142:1-53

Namasivayam C, Yamuna RT (1995) Adsorption of direct red 12 B by biogas residual slurry: equilibrium and rate processes. Environ Pollut 89:1-7

Nickson P, McArthur J, Burgess W, Ahmed KM, Ravenscroft P, Rahmann M (1998) Arsenic poisoning of Bangladesh groundwater. Nature 395:338

Ohki A, Nakayachigo K, Naka K, Meeda S (1996) Adsorption of inorganic and organic arsenic compounds by aluminium-loaded coral limestone. Appl Organomet Chem 10:747-752

Rouquerol J, Avnir D, Fairbridge CW, Everett DH, Haynes JM, Pernicone N, Ramsay JDF, Sing KSW, Unger KK (1994) Recommendations for the characterization of porous solids. Pure Appl Chem 66:1739-1758

Saha S, Sarkar P (2012) Arsenic remediation from drinking water by synthesized nano-alumina dispersed in chitosan-grafted polyacrylamide. J Hazard Mater 227-228:68-78

Shihabudheen M, Atul S, Kumar M, Ligy P (2006) Manganese-oxidecoated alumina: a promising sorbent for defluoridation of water. Water Res 40:3497-3506

Singh TS, Pant KK (2004) Equilibrium kinetics and thermodynamic studies for adsorption of As(III) on activated alumina. Sep Purif Technol 36:139-147

Sushree ST, Ashok MR (2008) Abatement of fluoride from water using manganese dioxide-coated activated alumina. J Hazard Mater 153:1043-1051

Thirunavukkarasu OS, Viraraghavan T, Subramanian KS (2003) Arsenic removal from drinking water using iron oxide coated sand. Water Air Soil Pollut 142:95-111

Uzasc1 S, Tezcan F, Erim FB (2014) Removal of hexavalent chromium from aqueous solution by barium ion cross-linked alginate beads. Int J Environ Sci Technol 11:1861-1868

Wang L, Chen ASC, Sorg TJ, Fields KA (2002) Field evaluation of As removal by IX and AA. J Am Water Works Assoc 94:161-173 
WHO (1981) Arsenic environmental health criteria. World Health Organization, Geneva, pp 43-102

Xu T, Nakajima Y, Ohki A (2002) Adsorption and removal of arsenic from drinking water by aluminum-loaded Shirasu-zeolite. J Hazard Mater B92:275-287
Zulfikar MA, Setiyanto H, Wahyuningrum D, Mukti RR (2014) Peat water treatment using chitosan-silica composite as an adsorbent. Int J Environ Res 8:687-710 